\title{
El Museo de los PP Paules de Villafranca del Bierzo (León) y su monetario
}

\author{
Manuel Abad Varela*
}

A la memoria de Leoncio Abad Trancón, mi padre, quien desarrolló su primer magisterio en Corullón.

Villafranca del Bierzo es uno de los más bellos enclaves naturales, no sólo por sus encantos paisajísticos sino también por la atmósfera que se respira a través de sus edificaciones y sus gentes que termina por envolver al que la contempla. Si alguno lo duda no deje de visitarla cuando se acerque al extremo de la provincia de León porque quedará embelesado, aunque sólo sea dirigiendo su mirada desde la carretera que conduce a Galicia '

Dentro de las importantes edificaciones con que cuenta esta villa, destaca la monumental iglesia de San Nicolás con su inmensa fachada barroca atribuida a Francisco de Mora, además del edificio anexo, antiguo Colegio de la Compañía de Jesús, que hoy regentan los PP. Paúles. La edificación de todo el conjunto debió iniciarse en 1613, gracias a la disposición y generosa aportación del Sr. de Robles, natural de Villafranca, quién mandó a su muerte que una renta de dos mil ducados fuese destinada para la Fundación de un Colegio de Jesuitas en Villafranca. Éste debió de terminarse hacia 1637, aunque debieron de comenzar a utilizarlo varios años antes, ya que en 1625 se conoce la organización de un acto Concepcionista celebrado por los PP. de la Compañía de Jesús ?

* Departamento de Prehistoria e Historia Antigua. UNED.

1 Si el lector necesita una guía, cuenta con las obras de QuINTANA y FERnÁndez, A.: Guía del Bierzo, León, 1965, págs. 32-41 o la de VOCES JoliAs, J. M., y IGLESIAS, J. M.: El Bierzo, edic. Lancia, León, 1989, págs. 75-87.

2 Buels Alonso, Ma M. de los: «El Santísimo Cristo de la Esperanza y San Nicolás el Real», Carqueixa, Villafranca, 1990, pág. 22. 
mientras que la iglesia, según figura sobre un arco lateral de la misma, se concluyó en $1649^{3}$.

La aparición en el Bierzo de este Colegio de Jesuitas supuso un gran acontecimiento cultural, pues venía a fortalecer las posibilidades de educación y formación, no sólo de los habitantes de esta noble villa, que ya contaban con otro centro, sino de toda la comarca. Su aparición mejoraba las expectativas de enseñanza, por considerar a estos colegios de jesuitas los centros educativos más importantes y avanzados de la época.

Es probable que este deseo del Sr. de Robles, quien siempre se confesó como natural de Villafranca del Bierzo, naciese de su relación con esta congregación durante su estancia en Potosí, lugar donde ocupó, por compra, el primer puesto de tallador de su ceca.

Pues bien, tras la expulsión de los jesuitas en 1767 estos edificios pasaron a los Goyanes, a través del Patronato Real de Legos, y de éstos a los PP. Paúles quienes llegaron en 1899 para hacerse cargo del colegio, que acababan de comprar a Dña. Teresa Goyanes ${ }^{4}$. Aquí establecieron el Colegio Seminario de la Milagrosa hasta que hace poco pasó a cumplir funciones de Residencia ${ }^{5}$. La iglesia se la cedería a su llegada el prelado de Astorga en usufruto perpetuo.

\section{EL MUSEO DE CIENCIAS NATURALES}

El Museo de Ciencias Naturales, del que vamos a hablar ahora, se encuentra ubicado en el claustro del antiguo Colegio y en una de las salas contiguas. Desgraciadamente no es muy conocido ${ }^{6}$, aunque por ello no

3 Gómez Moreno, M.: Catálogo monumental de la provincia de León, Madrid, 1925, pág. 387, láms. 555-557.

4 BueIS ALONSO, M" M. de los: Opus cit, págs. 22 y 23.

5 Debo hacer constar mi agradecimiento al antiguo director, P. ANTONıO AIRAS PAJE, como al actual P. BERNARDO LORENZO por su amabilidad, facilidades e informaciones, sin las cuales no hubiese podido llevar a cabo este estudio.

6 De hecho no se le incluye ni en la guía de Llamazares, F.: Museos de León y Provincia, ed. Nebrija, colección Turismo, León, 1985, ni en las editadas por la Junta de Castilla y León. Podemos decir que lo da a conocer, por primera vez de una manera monográfica en 1993, Miguel Pérez: Villafranca del Bierzo. Museo de Ciencias Naturales P. P. Paules, dentro de la serie Museos y Colecciones de León, publicada por La Crónica 16 de León con el patrocinio de la Diputación de León, la Junta de Castilla y León y el Ayuntamiento de León, con el $n{ }^{\circ} 8$. 
deja de ser visitado por los escolares de la zona e incluso de otras provincias que llegan en autocares.

Se sabe que la formación del mismo tuvo su origen en la partición de un gran museo que se había iniciado entre los años 1894 a 1899 en el Colegio Seminario de Madrid ${ }^{7}$, como todavía se puede comprobar por alguna de las etiquetas que acompañan a las piezas expuestas.

La creación de este tipo de museos, como el del Colegio Seminario de Madrid, entronca con el largo proceso iniciado por los intelectuales del siglo XVIII. Ellos se inclinaban hacia las ciencias clásicas, las experimentales, que al ser realistas y positivas seguian la misma dirección que marcaba la nueva filosofía empírica. Se trataba de una reacción contra los antiguos estudios teológicos, metafísicos y de pura teoría al mismo tiempo que suponía, para los científicos españoles del momento, una vuelta al pasado donde tanto habían descollado nuestros hombres de ciencia. Esta situación quedó reflejada en todas las reformas de la enseñanza que se introdujeron, incluso se puso de moda la creación en las casas de gabinetes de experimentación, como se les llamaba entonces. Comenzaron a brillar a partir de entonces con luz propia las ciencias naturales, entre ellas, principalmente, la botánica, mineralogía y zoología. Hasta tal punto que la historia natural pasó a ser, durante el siglo XIX, una asignatura obligatoria en los estudios de medicina y cirugía así como en los institutos de segunda enseñanza. A partir del año 1870 los planes de estudios reúnen en una sola asignatura la historia natural, la fisiología y la higiene. Para llevar a cabo los mismos se hizo necesario disponer de gabinetes de historia natural y física.

El Ministerio de Fomento se propuso dotar a los centros educativos con material pedagógico y experimental suficiente. Para tal fin, encargó a la Comisión del Mapa Geológico la formación de colecciones que serían destinadas a los mismos. El museo del Colegio Seminario de Madrid, nació dentro de esta política y, como otros museos se fueron enriqueciendo sus colecciones poco a poco con distintas aportaciones, principalmente, de misioneros que traían o enviaban piezas de América y Filipinas, tales como aves y moluscos.

7 Fernández Álvarez, A., y Recio González, M. I I.: Museo de Ciencias Naturales Colegio PP. Paúles, Villafranca del Bierzo (León). Cuaderno de Actividades, Primera parte 1.- Aves, 2.Conchas de moluscos. Villafranca del Bierzo, s/f (fotocopia). 
Pero, como dijimos, este museo del Colegio Seminario de Madrid se dividió entre las Casas colegiales de los PP. Paúles de Munguía, Limpias y Villafranca del Bierzo, por esta razón el actual Museo de Ciencias Naturales, del que nos ocupamos, constituye la tercera parte de lo que en su día fue un único museo.

Éste sería el origen del Museo de Villafranca del Bierzo. A pesar de todo, no quedó anclado en el pasado. A lo largo de todo este tiempo ha permanecido vivo, y por tanto ha sufrido los distintos avatares propios de todos los museos. Algunos ejemplares, en momentos malos y de abandono, se fueron deteriorando hasta perderse, pero también, en circunstancias mejores, el número de piezas expuestas aumentó y se completaron algunas colecciones por medio de distintas aportaciones, a veces con piezas rarísimas, gracias a la generosidad y entusiasmo de muchas personas.

En la actualidad, los PP. Paules se han propuesto actualizarlo, mejorando su exposición de tal manera que, al mismo tiempo que se ve, se obtenga una buena información. Todo ello buscando el mayor rendimiento educativo posible. Con este fin se han editado, además, Cuadernos de Actividades de alto grado educativo que sirven para completar pedagógicamente las visitas ${ }^{8}$.

Entre los objetos que se pueden contemplar expuestos en las numerosas vitrinas hay: colecciones de conchas y aves, así como diversos ejemplares de mamíferos, reptiles y peces. Numerosos invertebrados y algunos fósiles, entre los que destacan unos buenos ejemplares de la «rana de libros», además de minerales, rocas y una variadísima colección de maderas.

Cuenta también con algunas piezas arqueológicas entre las que sobresale un ídolo ovoide con representación en anverso y reverso, posiblemente de la Edad del Bronce, y varias hachas neolíticas ${ }^{9}$.

Finalmente, posee una pequeña colección de monedas, que no se encuentra expuesta al público, y que son las que nos proponemos estudiar en el presente trabajo.

8 Como el Cuaderno de Actividades para Aves y Conchas realizado por FERNÁNDEZ ÁLVAREZ, A., y Recio González, M. ${ }^{\text {a }}$ I.: Op. cit.

9 Se pueden ver reproducido en la obra de Miguel Pérez: Op. cit., pág. 20. 


\section{MONETARIO}

Supimos de la existencia de este conjunto de monedas en el museo por una referencia del profesor de la Universidad de Valladolid, Tomás Mañanes ${ }^{10}$.

Puestos al habla y por carta con el entonces rector del Seminario de la Milagrosa de los PP. Paúles, padre Antonio Airas Paje, nos informó que no eran tres las piezas que contenía sino seis. A nuestra solicitud sobre el lugar de procedencia, nos dijo: «No hay nada escrito, pero en el año 1950 en el que un servidor estudiaba aquí Humanidades, el Padre encargado del museo nos decía que se habían encontrado en el castro romano de La Ventosa, cerca de Cacabelos» ${ }^{11}$.

Aprovechando uno de nuestros pasos hacia Galicia, concertamos una entrevista para estudiar este pequeño monetario, teniendo la oportunidad de hacerlo el 6 de junio de $1987^{12}$.

\section{Catálogo}

Número 1:

Tiberio (14-16)

Leyenda anverso: (De dcha. a izq. leyendo por fuera) TI. CAESar. diVI. AVGVSTi. f. aVgvstVS.

Descripción: Busto laureado a dcha.

Ley. reverso: Sin leyenda.

10 Mañanes Pérez, Tomás: «Hallazgos numismáticos en El Bierzo (León)», Numisma, XXVI, no 138-143, enero-diciembre, 1976. En la pág. 113 nos da una cita, incompleta, de las piezas que contiene: «Existen dos monedas hispano latinas, una de Calagurris, y otra de Caesaraugusta, y un pequeño bronce de Constantino; su procedencia es incierta.

A./ Cabeza a la dcha, diademada y con ínfulas. IMP CONST NVSPF AUG

R./ Sol, a la izquierda, con corona de rayos. SOLIINVI CTO COMITI,

Exergo: SRAL.

MEDIDAS: $20 \mathrm{~mm}$. Ejes II (flechas hacia arriba)

Conservación: buena

Bibliografía RIC, VII».

11 Carta con fecha $23 / 3 / 87$, respondiendo a la nuestra del 10/3/87.

12 En nuestra entrevista, nos comentó el Padre Antonio Airas que probablemente habrían sido recogidas en las visitas que los seminaristas hacían a aquella zona, aunque esto último no lo podía afirmar con seguridad. 
Descripción: Toro mitrado a dcha. apoyado sobre una linea, y encima C.C.A

Ceca: Caesar Augusta.

Tipo: as; metal: Ae; peso: 20,600 gr.; módulo: $27 \mathrm{~mm}$.; grosor: $2 \mathrm{~mm}$;; ejes: 3; conservación: MM.

Referencia bibliográfica: Villaronga, L.: Numismática antigua de Hispania, Barcelona, 1979, pág. 284, n. ${ }^{\circ}$ 1.088; Álvarez Burgos, F.: Las monedas españolas, vol. I, "La moneda Hispánica desde sus orígenes hasta el siglo v", ed. Vico \& Segarra, Madrid, 1987, pág. 63, n. 268.

Número 2:

Tiberio (14-36)

Ley. anv.: (De dcha. a izq. leyendo por fuera) TI CAESAR DIVI AVG ...

Descripción: Busto laureado a dcha.

Ley. rev.: (De izq. a dcha.) Arriba G. Celere, abajo G. Recto, detrás del toro M.C.I. y delante II/VIR

Descripción: Toro a dcha. apoyado sobre una línea.

Ceca: Calagurris

Tipo: as; metal: Ae; peso: 20,175 gr.; mód.: 28 mm.; gros.: 2 mm.; ej.: 9; cons.: $M$.

Ref. bibl.: Villaronga, L.: Numismática Antigua de Hispania, Barcelona, 1979, pág. 283, n. ${ }^{1}$ 1.086; Álvarez Burgos, F.: Op. cit., pág. 71, n. ${ }^{\circ} 326$; Ruiz Trapero, $\mathrm{M}^{\mathrm{a}}$ : Las acuñaciones hispanorromanas de Calagurris, Barcelona, 1968, pág. 112-113, no 25.

Número 3:

Constantino I (313-315)

Ley. anv.: IMP CONSTANTINVS P F AVG

Descripción: Busto laureado a dcha. con manto y coraza.

Ley. rev.: SOLI IN-V-ICTO COMITI 
Descripción: Sol en pie, a la izq. con clámide resbalando sobre el hombro izq. y sujetada por el brazo izq. mientras sostiene en la mano el globo y la dcha. en alto.

Exergo: SARL Ceca: Arlés, $2^{\mathrm{a}}$ oficina.

Tipo: nummus; metal: Ae; peso: 3 gr.; mód.: 20 mm.; gros.: 1,5 mm.; ej.: 12; cons.: R.

Ref. bibl.: RIC VII, pág. 237 , n⿳ 40 , con la variante indicada en la nota $40,-\mathrm{V}$ -

Número 4:

Constancio II (355-361)

Ley. anv.: D N ...nSTAN - TIVS PF AVG

Descripción: Busto laureado a dcha. con manto y coraza.

Ley. rev.: FEL TEMP - REPARATIO

Descripción: Virtud en pie mirando a la izq. con escudo en brazo izq.; alanceando a jinete caído por encima del caballo a su dcha.; mientras apoya su rodilla dcha. sobre él; en el suelo a la dcha. el escudo.

Exergo: ANS Ceca: Antioquía, 6ª , oficina.

Tipo: nummus; metal: Ae; peso: 1,900 gr.; mód.: 17 mm.; gros.: 1,5 $\mathrm{mm}$; ej.: 11; cons.: M (rota).

Ref. bibl.: RIC VIII, pág. 528, n. ${ }^{\circ} 188 ;$;RBC, pág. 100, n. $^{\circ} 2.635$.

Número 5

Constancio II (355-361)

Ley. anv.: ...

Descripción: Busto diademado a dcha. con manto y coraza.

Ley. rev.: fel temp re - paRATIO

Descripción: Virtud en pie mirando a la izq. con escudo en brazo izq.; alanceando a su dcha. a un jinete caído sobre el caballo que levanta un 
brazo; mientras apoya su rodilla dcha. sobre él; en el suelo a la dcha. el escudo.

Exergo: CONS? Ceca: Constantinopla, oficina ¿ ?.

Tipo: nummus; metal: Ae; peso: 1,900 gr.; mód.: 15 mm.; gros.: 1,3 mm.; ej.: 1; cons.: MM.

Ref. bibl:; RIC VIII, pág. 460, n. ${ }^{\circ} 135 ;$;RBC, pág. 87, n. ${ }^{\circ} 2.039$.

Número 6

Constancio II (355-361)

Ley. anv.: ...

Descripción: Busto diademado con roseta a dcha. con manto y coraza.

Ley. rev.: (tipo Fel Temp Reparatio)

Descripción: Virtud en pie mirando a la izq. con escudo en brazo izq.; alanceando a su dcha. a un jinete caído sobre el caballo que levanta un brazo; mientras apoya su rodilla dcha. sobre él; en el suelo a la dcha. el escudo.

Exergo: SMK $\gamma$ Ceca: Cícico, $3^{\text {a }}$ oficina.

Tipo: nummus; metal: Ae; peso: 2 gr.; mód: 15 mm.; gros.: 1,1 mm.; ej.: 6; cons.: MM.

Ref. bibl.: RIC VIII, pág. 499, no 111; LRBC, pág. 97, no 2498.

\section{ESTUDIO}

Entre las seis piezas conservadas únicamente se encuentran representados el siglo I d. C. y el siglo IV.

Las dos primeras del catálogo corresponden al período de Tiberio, habiendo sido acuñadas en Caesar Augusta y Calagurris, respectivamente. Las piezas procedentes de estas cecas suelen ser las que están más presentes en la zona del noroeste. El hecho habría que relacionarlo con el movimiento de tropas y el auge de las explotaciones mineras en este área durante el siglo $\mathrm{t}$. Esto último motivará un gran desarrollo comercial y de comunicación entre la zona noroeste y el valle del Ebro a través de las 
vías no 18,19 y 20 que conducian desde Italia hasta Brácara, según el Itinerario de Antonino ${ }^{13}$ lo acredita. La abundancia con que aparecen en El Bierzo las cecas del valle del Ebro, al mismo tiempo que nos hace pensar que era por donde se daba salida a gran parte de los productos mineros.

El resto de las monedas corresponden una al 313-315 y las tres restantes al período comprendido desde el 355 al 361.

Teniendo en cuenta la tónica general de las monedas que se encuentran en El Bierzo, nos sorprende este conjunto, ya que lo normal es que, en las colecciones que visitamos, no aparezcan tantas monedas del siglo IV d. C., salvo en los hallazgos de conjunto o depósitos cerrados. No obstante, quiero entender que esto obedece a razones casuales y de falta de estudios de hallazgos en la zona.

Los lugares donde han sido acuñadas corresponden, la primera, a la ceca gala de Arlés y, las tres restantes, a las orientales de Antioquía, Constantinopla y Cícico.

La aparición de piezas acuñadas fuera de nuestra Península no supone nada especial, teniendo en cuenta que en Hispania en todo el siglo IV no hubo ningún taller funcionando.

Durante la era Constantiniana (313-337), en que queda comprendida la moneda de Constantino I, el mayor porcentaje de monedas que llegaron a la península lbérica estaba labrado en Roma y Arlés ${ }^{14}$. El que se encuentre una moneda de Constantino I, acuñada en Arlés, es lo más normal.

Llama algo la atención que las otras tres de Constancio II pertenezcan a talleres orientales tan lejanos. Sabemos que el período que va desde la reforma monetaria de Constante y Constancio II (348) hasta la muerte de Juliano II (364) los talleres que abastecen principalmente a la Península son los galos e itálicos con el 72,53 por ciento, mientras que a las cecas balcánico-danubianas de Tracia, Asia Menor y las propiamente orientales les corresponde el resto, el 27,47 por ciento ${ }^{15}$. Entre este último grupo, las que más se encuentran representadas en la Península son las de Constantinopla y Cícico, correspondiendo, en este caso, con las que te-

13 Roldán Hervas, J.M.: Itineraria Hispana, fuentes antiguas para el estudio de las vías romanas en la Península Ibérica, Anejo de Hispania Antiqva, Vitoria, 1973, págs. 71-77.

14 Abad Varela, M.: «Representación en Hispania de las cecas existentes desde el 284 al 395 d.C. ", Gaceta Numismática, IV, 99, Barcelona, 1990, págs. 22-23.

15 ABAD VARELA, M.: Op. cit. (1990), págs. 24-25. 
nemos. Conviene señalar, no obstante, que a partir del 355 se va a ir incrementando la llegada a nuestra Península de monetario acuñado en talleres de la parte Oriental. Este hecho nos da como resultado que en el período del 364 al 395 las cecas orientales que se encuentran en Hispania constituyan el 47,91 por ciento ${ }^{16}$. Pero a pesar de todo, no tenemos que olvidar que Hispania estuvo también abastecida abundantemente, desde el 348 hasta el 395, por los talleres galos e itálicos.

El hecho de que, aunque en tan poco número, no aparezcan representadas sus cecas en El Bierzo, nos podría hacer suponer que el abastecimiento monetario y, por tanto los contactos comerciales durante este período del siglo IV no llegan por las vías tradicionales del siglo I, sino que se recibe por vía marítima. Pero esto hay que reconocer que es una mera hipótesis puesto que el número de piezas analizadas con las que se cuenta es tan escaso que resulta imposible realizar cualquier matización. Esperemos que en el futuro se vayan dando a conocer todos los hallazgos a medida que se produzcan.

Lamentamos que el estado de conservación de las tres últimas nos impida precisar si corresponden a piezas de imitación, aunque por tratarse de un módulo tan pequeño nos podría hacer pensar en esta hipótesis.

Finalmente, deseamos que este sencillo estudio sirva para conocer mejor este Museo de la provincia de León. A su dirección le animamos a seguir su importante labor pedagógica al servicio de las ciencias y a que no se olviden de alimentar el pequeño monetario con aquellas otras monedas que vayan apareciendo fortuitamente en la zona. Pues estoy seguro que al fundador de tan espléndida obra, Gabriel de Robles, nada le hubiese agradado más saber que aquel edificio, que él había sufragado en su día con los beneficios obtenidos en Potosí, servía también para albergar ahora un monetario con aquellas piezas antiguas halladas en la tierra que él tanto quiso.

16 Abad Varela, M.: Op. cit. (1990), págs. 26-27. 


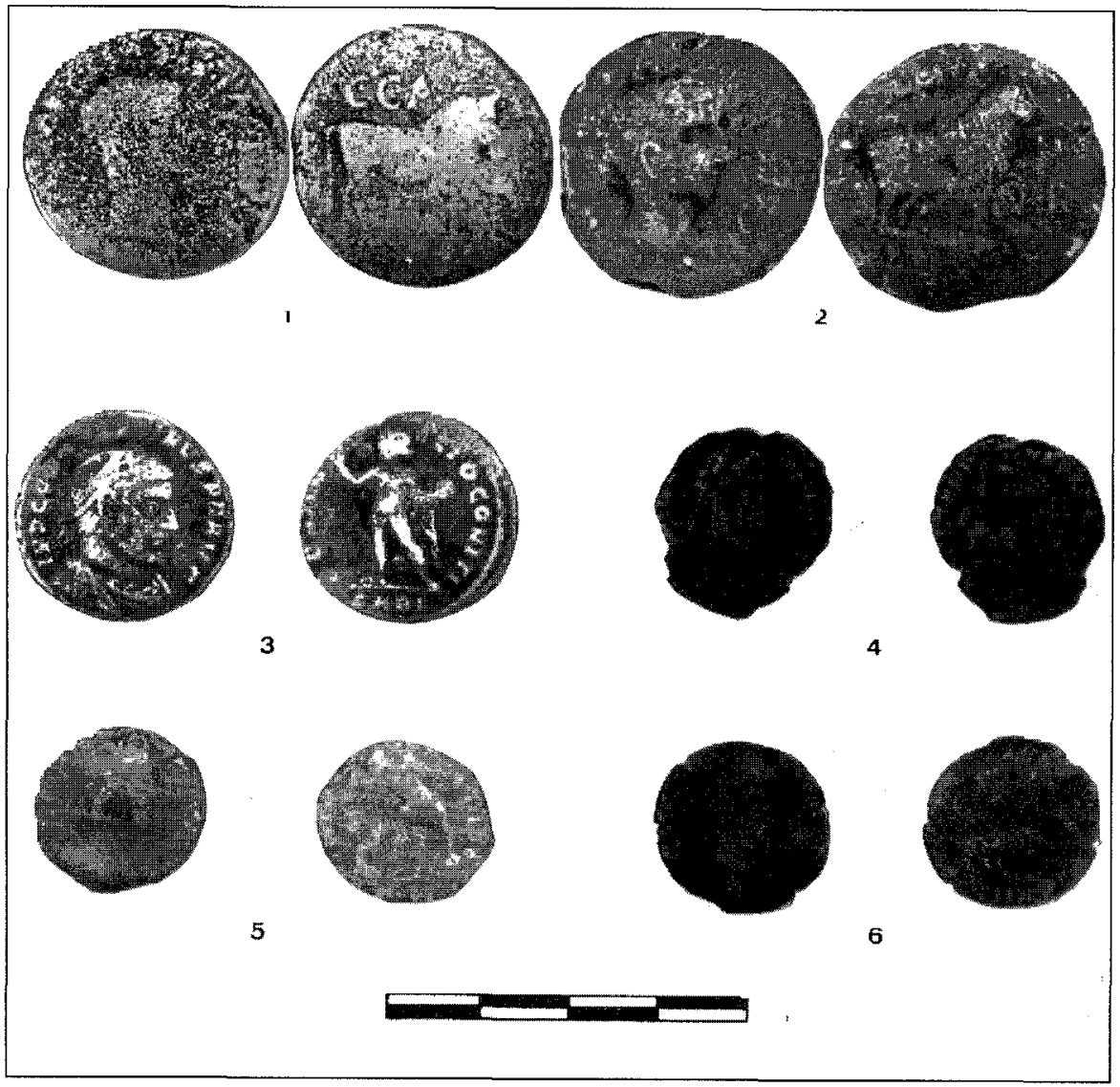

Selección del Monetario del Museo de los PP Paules de Villafranca del Bierzo 